\title{
The effect of an online active learning-based course on approaches to teaching
}

Mansurbek Kushnazarov, Crystal Jing Luo, Nicole Kwan Yee Lai

Center for Education Innovation, Hong Kong University of Science and Technology, Hong Kong S.A.R.

\begin{abstract}
The quality of teacher training research postgraduate $(R P g)$ students receive is highly likely to determine the quality of teaching and learning they will provide when they are given teaching duties. Designing and developing such a teaching development course is considerably challenging, particularly if it is fully online. Owing to its focus on student learning, we integrated group learning, case-based learning and technology-enhanced learning approaches of active learning into an online Professional Development (PD) course at a university in Hong Kong. The course intended to enhance RPg students' student-focused teaching approaches which, in turn, would help their students demonstrate high academic performance and achieve learning objectives. We relied on the concept of teaching approaches to build the theoretical foundation of this study and used Approaches to Teaching Inventory (ATI) to test the effectiveness of the PD course in improving the RPg students' teaching quality. The quantitative analysis of the survey conducted showed that there was a significant increase in both Conceptual Change/Student Focused (CCSF) and Information Transmission/Teacher Focused approaches to teaching among the RPg students. The results provided opportunities to make informed decisions for further enhancement of the course design and start a new potential dialogue in studies of teaching approaches.
\end{abstract}

Keywords: Approaches to teaching; active learning; student-focused learning; online course design; professional development; teacher training. 


\section{Introduction}

It is widely acknowledged that there has been a transformation in higher education teaching and learning from an instructor-focused approach to a learner-centered approach (Barr \& Tagg, 1995). Such paradigm shift is a result of evidence from the fields of Learning Science, Cognitive Science and Educational Psychology that supported the effectiveness of active learning in facilitating student-centered learning to achieve educational objectives on all levels of education (Michael, 2006). As a constructivist method, active learning emphasizes the importance of focusing on what the student learns and how, rather than the methods and materials the teacher uses to teach. There are several categories of active learning that effectively support student-centeredness of the teaching and learning process (Harold \& Joel, 2003). Referring to the principle of 'teach as you preach', Struyven et al. (2010) found that there was a strong relationship between the methods of teaching and learning used for training pre-service teachers and their perceived approaches to teaching. The authors explicated that the pre-service teachers' tendency to implement a student-centered teaching approach was a result of them receiving student-activated teaching during the training. Several studies supported the linkage between the quality of teacher training and approaches to teaching (Gibbs \& Coffey, 2004). While the scientific community advocate the assumption that student teachers learn from the way they are taught and will apply the same teaching approaches when they are expected to teach in the future in traditional 'brick and mortar' universities, there is still a strong need for empirical evidence to support such claim within virtual realms of higher education. Therefore, this study aimed to help enrich the literature by investigating how the online active learning-based design of a Professional Development (PD) course would shape research postgraduate (RPg) students' approaches to teaching. By adopting some of the active learning approaches in its fully online design, the PD course planned to develop a more student-focused teaching approach among the RPg students than a teacher-centered approach. The extent to which the RPg students adopted a more studentcentered approach or a more teacher-centered approach was evaluated using Approaches to Teaching Inventory (ATI) by Prosser and Trigwell (1999). In the following sections, the theoretical background and relevance of ATI will be explored thoroughly followed by a detailed description of how the online PD course incorporated active learning approaches to equip the RPg students with student-focused teaching methods.

\section{Approaches to Teaching}

The concept of Approaches to Teaching was initiated by Prosser et al. (1994) who studied the main variations of 24 university science teachers' conceptions of teaching and identified the following five main categories: (a) teaching as transmitting concepts of the syllabus, (b) teaching as transmitting the teachers' knowledge, (c) teaching as helping students acquire concepts of the syllabus, (d) teaching as helping students acquire the teacher's knowledge, 
and (e) teaching as helping students develop conceptions. The end result was the construction of ATI with two main scales of Information Transmission/Teacher Focused (ITTF) and Conceptual Change/Student Focused (CCSF) with overall 16 items (Trigwell et al., 1999). While self-descriptive, the ITTF approach is concentrated on transferring factual information to students without consideration of their prior knowledge and the importance of active learning whereas the CCSF approach is to help students construct their knowledge actively and the teacher is there to facilitate the learning process (Trigwell \& Prosser, 1996).

When preparing the theoretical background of the study, we faced the issue of limited up-todate literature on the influence of teaching development courses on approaches to teaching (Gonzalez, 2009). Though dated and little, the existing literature on the use of ATI to measure the effect of PD and training courses on teaching approaches helps shed a fair light on the common trends in the area. Struyven et al. (2010) studied the effect of a 'student-actived' course design on child development on Year 1 pre-service undergraduate students' perceived approaches to teaching in comparison to the impact of a traditional lecture course that taught the same subject. Although both groups achieved statistically significant differences between the pre-test and the post-test, the authors found that those who received the traditional lecture treatment demonstrated higher results than their counterparts in the 'student-activated' group in both CCSF and ITTF. In contrast, Gibbs and Coffey (2004) reached different results from a year-long investigation of teaching approaches of newly appointed teachers who received teacher training and those who did not. While the training group achieved a significant shift in CCSF, the control group showed no noticeable changes in either CCSF or ITTF. In a similar study, academics from 7 research-intensive universities in the UK were invited to complete the 22-item version of ATI (Trigwell \& Prosser, 2004) before and after completing an accredited teaching development programme (Hanbury et al., 2008). The findings showed that the participants perceived their teaching approach to be more CCSF and less ITTF after the completion of the training. Similar findings were reported in Finland where 200 university teachers with different years of work experience scored significantly higher in CCSF and lower in ITTF after completing pedagogical training than before (Postareff et al., 2007). While these past studies are relatively informative with regards to the appropriate use of the inventory, we could not draw direct parallels between them and the PD course design being evaluated in this paper due to lack of relevant and up-to-date literature. Therefore, this work aims to fill the literature gap by investigating the role of the active learning-based fully online PD course in shaping the RPg students' perceived approaches towards teaching.

\section{Active learning-based course setting}

The PD course consists of five modules providing an introduction to teaching and learning in higher education and is a graduation requirement for all RPg students at the university. The course is conducted to better prepare RPg students for their Graduate Teaching Assistant 
(GTA) duties which include teaching undergraduate students as tutors. After completing all the course requirements, RPg students proceed to carry out their GTA duties arranged by their home department. In outlining the alignment between certain active learning approaches and the major elements of the PD course, we follow the categorization proposed by Harold and Joel (2003): case-based learning, group learning, and technology-enhanced learning.

\subsection{Active learning through case-based learning}

In case-based learning, knowledge and skills are constructed through the process of solving complex, real-life problems which the learner will encounter and be expected to solve in the future (Harold \& Joel, 2003; Williams, 1992) such as the GTA duties. The learning activities and assessments in the PD course are designed to develop active teaching techniques in a learner-centered classroom (Module 1) by adopting effective presentation and facilitation strategies (Module 2) and giving constructive feedback to students (Module 3). They also need to master the use of Canvas ${ }^{1}$ (Module 4), the Learning Management System adopted by the university, before consolidating the teaching and learning principles in a peer-evaluated micro-teaching session (Module 5). Micro-teaching is the most important learning exercise of the course that encompasses all five modules and functions as the final assessment task. The design of micro-teaching reflects the GTA duties which involve designing learning activies and materials, delivering tutorials, evaluating student performance, and providing timely and constructive feedback.

\subsection{Active learning through group learning}

Most of the learning activities and assessments of the PD course are designed for group learning. Six to seven students from similar disciplines were grouped together throughout the course duration. The rationale behind putting students with identical backgrounds into groups was to allow them to have more in-depth discussions and collaboration when completing the online synchronous group learning activities and designing the final micro-teaching demonstration. The online group learning activities entailed intensive communication, collaboration, and negotiation among group members. For instance, in the activity of developing Intended Learning Outcomes for the 50-minute tutorial, team members discussed each others' ideas, evaluated their pros and cons, debated and negotiated to come to an agreement on the final response. During the process, we believe that group learning enabled the students to learn from each other, develop soft skills, and engage actively with the learning materials, all of which support active learning (Harold \& Joel, 2003).

\footnotetext{
${ }^{1}$ Canvas is a learning management system (LMS) for instructors to design interactive courses by customizing course content, quizzes, discussion and others.
} 


\subsection{Technology-enhanced active learning}

Due to the COVID-19 pandemic, the university shifted all the teaching and learning activities to an online mode in the Fall semester of 2020. The previously flipped design of the PD course was adjusted to be delivered fully online; while the pre-class and post-class materials and activities were already made available for self-paced online learning, the in-class components were redesigned for weekly online synchronous sessions. Prior to the synchronous sessions, the students were to cover all the learning materials such as lecture videos and supplementary readings on Canvas. Also, they were given online knowledgecheck quizzes to complete.

The PD course facilitated a highly interactive online learning environment for students to actively engage in. Zoom ${ }^{2}$ was used to conduct the synchronous sessions as well as breakout room group discussions while Miro $^{3}$ was adopted for groups to draft their ideas in the inclass activities, document assignment progress, and prepare the final micro-teaching lesson plan. On Miro, each group was allocated a separate 2D box-shaped working board area for virtual collaboration and co-creation. In each module, there were three learning activities for groups to work on through discussion and application of the theories and concepts learned. The use of Miro in the online course not only provided the students with the opportunity to co-create and learn from each other but also allowed them an authentic experience of facilitating an active learning environment, which is valuable for their future teaching.

\section{Methodology}

\subsection{Participants}

The RPg students enrolled in the PD course in the Fall semester of the 2020-2021 academic year at a university in Hong Kong were invited to participate in this study. There were 656 students enrolled in the course divided into 6 cohorts. The gender ratio in the course was $66 \%$ male students to $34 \%$ female students. The students were from various $\mathrm{PhD}$ and MPhil programmes across Schools of Science, Engineering, Business and Management, Humanities and Social Sciences as well as interdisciplinary institutes of the university. The response rates of the pre-test and the post-test surveys were $57 \%$ and $37 \%$, respectively. After data cleaning and matching, it was revealed that 193 students responded to both pre-test and post-test surveys which was equal to $29 \%$ of the course population. Of the 193 participants, $22.8 \%$ reported having some level of past teaching experience while the other $77.2 \%$ had not had

\footnotetext{
${ }^{2}$ Zoom is a video conferencing software that provides a video chatting service to multiple participants concurrently.

${ }^{3}$ Miro is an online collaborative whiteboard platform that allows users to co-create on a canvas-looking whiteboard in real-time.
} 
any prior experience in teaching. Most of the survey participants were from School of Engineering (50.3\%), School of Science (21.2\%) and Interdisciplinary Programs Office (9.8\%). Compared to the total course population, there was a fair representation of the mentioned schools of the university by the 193 participants.

\subsection{Survey procedure}

An online version of ATI was distributed to the RPg students before and after the course. In both cases, due to the fully online nature of the course, the survey link was placed on Canvas. The students were then invited to complete the survey voluntarily. Consent was granted by the survey participants regarding the use of their course enrolment data and survey responses for research and publication. IBM's SPSS Statistics 26.0 was utilized to carry out the quantitative analyses of the data collected.

\section{Results}

\subsection{Internal Consistency of ATI Scales}

In order to check the internal consistency of ATI with the target group, Cronbach's alphas of ITTF and CCSF were calculated for both pre-test and post-test surveys. The results showed that ITTF and CCSF demonstrated $\alpha=0.73$ and $\alpha=0.73$ in the pre-test and $\alpha=0.81$ and $\alpha=$ 0.79 in the post-test surveys, respectively. Alpha scores of 0.7 to 0.8 are commonly considered acceptable in social science research (Bland \& Altman, 1997).

\subsection{Changes in Approaches to Teaching}

The RPg students enrolled in the PD course were invited to complete ATI before and after the course in the Fall semester of the 2020-21 academic year. Paired sample t-tests were conducted to confirm if there had been any significant changes in the RPg students' approaches towards teaching. It was discovered that there was a statistically significant difference between the pre-test ITTF and the post-test ITTF at $t(191)=5.44, p<.001$. However, it was also observed that CCSF achieved a statistically significant shift between the pre-test and the post-test surveys with $t(191)=6.13, p<.001$. The details of the t-tests are given in Table 1. It is worth pointing out that the change in CCSF managed to achieve a statistical significance despite extremely high mean scores in the pre-test survey. 
Table 1. Paired samples t-test results of ITTF and CCSF.

\begin{tabular}{cccccc}
\hline Scales & Mean & Mean Differences & Std. Deviation & $\mathbf{t}$ & p-value \\
\hline Pre-test ITTF & 3.60 & -0.27892 & 0.70984 & 5.445 & .001 \\
Post-test ITTF & 3.88 & & & & \\
Pre-test CCSF & 3.95 & -0.24689 & 0.55764 & 6.135 & .001 \\
Post-test CCSF & 4.20 & & & & \\
\hline
\end{tabular}

\section{Conclusions}

Three active learning strategies were incorporated into the fully online design of the PD course with the intention of facilitating student-centered learning which, in turn, was expected to result in the development of CCSF teaching. The influence of the active learning elements on the RPg students' approaches to teaching was studied using ATI. The results showed that the students significantly improved not only CCSF approaches but also ITTF approaches to teaching. While the remarkable increase in CCSF was projected, a comparable trend in ITTF was not. The findings of the study are valuable in identifying which aspects of the PD course design are in parallel with the learning objectives and which areas still have room for improvement. They help the course team approach further enhancement of the online active learning design from a top-down approach as its general characteristics with regards to shaping RPg students' teaching approaches have been well uncovered. Having said that, a further empirical study of the underlying variables that determined the quantitative results is required, particularly the areas that could help explicate the improved ITTF among the RPg students after taking the course. It will also help to conduct a thorough qualitative evaluation of the course components and objectives as well as students' perceptions of approaches to teaching. In the meantime, the existing literature helps interpret the outcomes of the current quantitative analysis. Having studied the relations between teachers' approaches to teaching and their students' approaches to learning, Trigwell and Prosser (2004) concluded that the results deriving from ATI should be viewed from a contextual and relational perspective and that "the approach adopted by a teacher in one context may not be the same as the approach the same teacher would adopt in a different context." (p. 420). With respect to the main characteristics of differing teaching contexts that dictate which approaches to teaching are adopted, Prosser and Trigwell (1997) explained that those teachers who had appropriate teaching workload, homogenous and competent students, a manageable class size and a certain level of control over the teaching content tended to follow CCSF while those who neither saw a real commitment to teaching nor had control over what was taught were more inclined to adopt ITTF. In addition to the mentioned factors that determine which teaching approaches are preferred, it will also be worth investigating the role and 
influence of fully online course delivery and design where applicable. Such analysis is of a particular importance at the moment where conventional teaching and learning practices are not necessarily guaranteed and the only affordable method is through virtual means.

\section{References}

Barr, R. B., \& Tagg, J. (1995). From teaching to learning - A new paradigm for undergraduate education. Change: The magazine of higher learning, 27(6), 12-26.

Bland, J. M., \& Altman, D. G. (1997). Statistics notes: Cronbach's alpha. BMJ, 314(7080), 572. doi:https://doi.org/10.1136/bmj.314.7080.572

Gibbs, G., \& Coffey, M. (2004). The impact of training of university teachers on their teaching skills, their approach to teaching and the approach to learning of their students. Active learning in higher education, 5(1), 87-100. doi:https://doi.org/10.1177\%2F1469787404040463

Gonzalez, C. (2009). Conceptions of, and approaches to, teaching online: a study of lecturers teaching postgraduate distance courses. Higher education, 57(3), 299-314. doi:https://doi.org/10.1007/s10734-008-9145-1

Hanbury, A., Prosser, M., \& Rickinson, M. (2008). The differential impact of UK accredited teaching development programmes on academics' approaches to teaching. Studies in higher education, 33(4), 469-483. doi:https://doi.org/10.1080/03075070802211844

Harold, I. M., \& Joel, M. (2003). Active Learning in Secondary and College Science Classrooms: A Working Model for Helping the Learner To Learn. Mahwah: Mahwah: Taylor and Francis.

Michael, J. (2006). Where's the evidence that active learning works? Advances in physiology education. doi:https://doi.org/10.1152/advan.00053.2006

Postareff, L., Lindblom-Ylänne, S., \& Nevgi, A. (2007). The effect of pedagogical training on teaching in higher education. Teaching and teacher education, 23(5), 557-571. doi:https://doi.org/10.1016/j.tate.2006.11.013

Prosser, M., \& Trigwell, K. (1997). Perceptions of the teaching environment and its relationship to approaches to teaching. British Journal of Educational Psychology, 67(1), 25-35. doi:https://doi.org/10.1111/j.2044-8279.1997.tb01224.x

Prosser, M., \& Trigwell, K. (1999). Understanding learning and teaching: The experience in higher education: McGraw-Hill Education (UK).

Prosser, M., Trigwell, K., \& Taylor, P. (1994). A phenomenographic study of academics' conceptions of science learning and teaching. Learning and instruction, 4(3), 217-231. doi:https://doi.org/10.1016/0959-4752(94)90024-8

Struyven, K., Dochy, F., \& Janssens, S. (2010). 'Teach as you preach': the effects of studentcentred versus lecture-based teaching on student teachers' approaches to teaching. European Journal of Teacher Education, 33(1), 43-64. doi:http://dx.doi.org/10.1080/02619760903457818

Trigwell, K., \& Prosser, M. (1996). Congruence between intention and strategy in university science teachers' approaches to teaching. Higher education, 32(1), 77-87. 
Trigwell, K., \& Prosser, M. (2004). Development and use of the approaches to teaching inventory. Educational Psychology Review, 16(4), 409-424. doi:https://doi.org/10.1007/s10648-004-0007-9

Trigwell, K., Prosser, M., \& Waterhouse, F. (1999). Relations between teachers' approaches to teaching and students' approaches to learning. Higher education, 37(1), 57-70. doi:https://doi.org/10.1023/A:1003548313194

Williams, S. M. (1992). Putting case-based instruction into context: Examples from legal and medical education. The Journal of the learning Sciences, 2(4), 367-427. 